\title{
TOWARDS A CRITICAL REALIST COMPARATIVE METHODOLOGY \\ Context-Sensitive Theoretical Comparison
}

Published in Journal of Critical Realism 6(1) 2007, 5-27

Ann Cecilie Bergene, University of Oslo

a.c.bergene@sgeo.uio.no

Department of Sociology and Human Geography University of Oslo

P.O.Box 1096 Blindern

N-0317 OSLO Norway

Telephone: $\quad+4722855257$

Fax:

$+4722855253$

Internet: http://www.iss.uio.no 


\title{
TOWARDS A CRITICAL REALIST COMPARATIVE METHODOLOGY
}

\author{
Context-Sensitive Theoretical Comparison
}

BY

ANN CECILIE BERGENE ${ }^{1}$

\begin{abstract}
This article provides a critical realist take on comparative methodology. Heeding the call for greater attention to the ontological presuppositions inherent in all methods, it first outlines comparative methods as they have traditionally been conceived and practised. Discerning two important aspects of these approaches - their notion of causality and their reliance on inductive inferences - the discussion moves on to consider their applicability within a critical realist social science. Arguing that the ontological presuppositions of traditional approaches to comparative methodology are not compatible with the ontology of critical realism, it seeks to specify some initial steps in the direction of designing a new approach securing this compatibility. Important to this new approach is theoretical, or abductive, comparison and the need to be context-sensitive.
\end{abstract}

Key words: causality, modes of inference (abduction, induction, retroduction), comparative method, context-sensitivity.

\section{Introduction}

In this article I discuss the merits of comparative case studies as they have been practised in qualitative social science and take some steps towards developing an alternative mode of comparison informed by critical realism. The question of method in critical realism has been raised by several authors, but their preoccupations and answers vary. Henry Wai-chung Yeung argues that 'method in critical realism is underdeveloped and misunderstood, resulting in a methodologically handicapped philosophy'. ${ }^{2} \mathrm{He}$ is thus of the opinion that the time is ripe for a serious consideration of methodology in critical realist research.

1 Department of Sociology and Human Geography, University of Oslo, P.O. Box 1096 Blindern, NO-0317 Oslo, Norway.

2 Henry Wai-chung Yeung, 'Critical realism and realist research in human geography: a method or a philosophy in search of a method?’, Progress in Human Geography 21(1) (1997), 56. 
Berth Danermark et al. argue that, if a consistent connection between ontology and methodology is missing, then the employment of methods will be, if not wrong, then less fruitful. ${ }^{3}$ They are, however, very clear that they do not necessarily propose the development of a new method, but rather advocate the use of already existing methods within social science in a critical realist inspired practice. Furthermore, they propose methodological pluralism in the sense that different methods are appropriate to different situations. Still, reviewing Danermark et al.'s Explaining Society, Andrew Sayer concludes: 'The question remains, however: what next for critical realist methodology?'4 One of the already existing methods in social science where the implications of a critical realist ontology and epistemology have yet to be duly considered is comparative case studies. ${ }^{5}$ All methods have ontological presuppositions, and enquiring into these helps us avoid any mismatch between methods employed and the nature of the object under study. ${ }^{6}$ Danermark et al. highlight comparison as a possible strategy for discerning structures and mechanisms, and Tony Lawson has sought to develop an explanatory method, involving comparison, appropriate to an open, structured and internally related reality. ${ }^{7}$ However, when employing comparative methods, questions of ontology, epistemology and notions of theory and causation arise. One methodological problem with comparative case studies relates to the assumption about the nature of the social world that informs them. ${ }^{8}$ The idea behind at least some comparative research is that the social world is structured in terms of regularities that can be expressed as laws. This is especially important if these laws are assumed to be deterministic. If this is the case, then a single negative instance can falsify the initial hypothesis. I discuss the influence of this idea on comparative case studies below. If, however, scientific laws are, as in critical realism, treated in a more contingent or probabilistic manner, then the act of drawing theoretical conclusions from case studies becomes a much more complex matter. Another methodological problem concerns the procedure of abstracting from particular cases instead of treating each case as a whole and bounded system. Central to my concern is to avoid inclining to empiricism, and thereby to a synchronic and correla-

3 Berth Danermark et al., Explaining Society: Critical Realism in the Social Sciences [ES] (London: Routledge, 2002).

4 Andrew Sayer, 'Critical realist methodology: a view from Sweden', Journal of Critical Realism 1(1) (2002), 170.

5 Peter Wad, 'Komparation i kritisk realistisk perspektiv', Dansk Sociologi 11(3) (2000) and 'Critical Realism and Comparative Sociology' [CRCS], paper presented at the 5th IACR Conference, Roskilde, 2001.

6 Tony Lawson, Reorienting Economics [RE] (London: Routledge, 2003).

7 Danermark et al., ES; Lawson, $R E$.

8 Martyn Hammersley et al., 'Case study and theory' [CST], in Case Study Method: Key Issues, Key Texts, eds R. Gomm et al. (London: Sage, 2000). 
tional concept of causality and the propensity to favour parsimoniousness at the expense of context.

I argue that comparative case studies have much to offer a critical realist researcher, but that the approach to them needs to be reworked to be consistent with the philosophy of critical realism. This involves both reflecting on what conclusions might be drawn from the application of comparative case studies, and revising the procedures for comparing. The article is structured into three sections. First, I scrutinise the Mill-inspired approaches to comparative case studies by looking at the notion of causality at their basis and the mode of inference they imply. The second section presents a general introduction to some of the canons of critical realism as a philosophy, paying particular attention to the critical realist notion of causality and the preferred modes of inference. I also provide some arguments for why comparative case studies might provide a potential methodological avenue for critical realism. In the third section I move on to taking some initial steps towards developing an approach to comparative case studies informed by and compatible with the philosophy of critical realism. Lastly, I provide an illustration of how this approach could be used in practice.

\section{Millean Approaches to Comparative Case Studies}

The chief merit of comparative case studies is often said to be that it allows for an examination of patterns of similarities and differences across a moderate number of cases, thus combining depth with a more extensive approach. I argue that comparative case studies often implicitly or explicitly draw on the canons of John Stuart Mill and his methods for examining these patterns. According to Charles Ragin, the objective of comparative studies is often to unravel the different causal conditions underlying diverse outcomes. ${ }^{9}$ This relates it directly to a wider debate on the notions of theory and causation. There are, according to Martyn Hammersley et al., at least two influential interpretations of comparative methods implying different inductive inferences. ${ }^{10}$ I return to these interpretations after considering the notion of causality implicit in the Millean approaches.

\subsection{Causation as regularity}

Through the aspiration to identify the general causal conditions by examining patterns of similarities and differences across cases, comparative case studies are

9 Charles C. Ragin, Constructing Social Research: The Unity and Diversity of Method [CSR] (Thousand Oaks, CA: Pine Forge Press, 1994).

${ }^{10}$ Hammersley et al., CST. 
often informed by what Lars Mjøset terms the law-oriented notion of theory. ${ }^{11}$ Adopting this notion of theory implies regarding the social sciences as generalising and hence relying on empirical studies seeking to establish regularities. Theory is here conceived as organised knowledge about observable patterns, and 'comparison', in this instance, means empirically comparing several factual cases. Within the empiricist tradition it is argued that nothing can be known to be real unless it is observable. Hume thus claimed that cause is merely constant conjunction, and that there is no causality, that is, force or compulsion, in nature over and above invariant succession of events. ${ }^{12}$ This notion of causality is synchronic in that cause and effect must be both adjacent and temporally successive, and correlational in that the relation between them must be constant. ${ }^{13}$ Taking Hume's problem of induction as a point of departure, comparative studies often draw on the canons of Mill and his 'method of agreement' and 'method of difference'. The first canon, informing the method of agreement, states: 'If two or more instances of the phenomenon under investigation have only one circumstance in common, the circumstance in which alone all instances agree, is the cause (or effect) of the given phenomenon'. ${ }^{14}$ The canon behind the method of difference is:

If an instance in which the phenomenon under investigation occurs, and an instance in which it does not occur, have every circumstance in common save one, that one occurring in the former; the circumstance in which alone the two instances differ, is the effect, or the cause, or an indispensable part of the cause, of the phenomenon. ${ }^{15}$

Mill maintained that the only way to theorise causal mechanisms is through comparison, with the method of agreement focusing on similarities among cases showing the same outcome, and the method of difference on differences between cases with different outcomes. ${ }^{16}$ For him, as for those adhering to a Humean notion of causality, causal relations did not involve any necessity, but were merely regularities to be discovered. Mill, in turn, was inspired by the thinking of Francis Bacon. Bacon, working on a rejection of the deductivism of

11 Lars Mjøset, 'Theory: conceptions in the social sciences', in The International Encyclopedia of the Social and Behavioral Sciences, eds Neil J. Smelser and Paul B. Bates (Oxford: Elsevier, 2001).

12 Ian Hacking, Representing and Intervening: Introductory Topics in the Philosophy of Natural Science (Cambridge: Cambridge University Press, 1983); Andrew Abbott, Time Matters: On Theory and Method (Chicago, IL: University of Chicago Press, 2001).

13 Abbott, ibid.

14 John Stuart Mill, System of Logic, Ratiocinative and Inductive: Being a Connected View of the Principles of Evidence, and the Methods of Scientific Investigation, 5th edn (London: Parker, Son, and Bourn, 1843/1862), 428.

15 Ibid., 429.

16 Hammersley et al., CST. 
Aristotle, advanced a method relying on induction and giving greater force to the negative instance. ${ }^{17} \mathrm{He}$ thus argued that all relevant cases must be laid out and checked for presence, absence and degrees with the aim to identify what is 'always present or absent with the given nature, and always increases and decreases with it'. ${ }^{18}$ The key to comparative case studies is thus the selection of cases on the basis of differences in outcome, and a focus on their similarities and what distinguishes them.

Attempting to bridge the qualitative-quantitative divide, Ragin develops an approach called qualitative comparative analysis (QCA), which simultaneously combines many cases with many variables. ${ }^{19}$ As mentioned above, the approach is relatively context-sensitive, as he treats each case as a configuration, meaning that he pays heed to the complex of specific features that make each case unique, although simplification and elimination are central to his method. ${ }^{20}$ In addition, the approach is open to multi-causality, as the analysis seeks to discover what caused a specific effect through configurations of variables. However, although assuming that an effect can have multiple causes, it is assumed that only one causal configuration can produce one effect. The configurations are plotted in matrices, and Ragin's method operates with binary factors for description and explanation of the cases, or what he terms 'presence-absence dichotomies'. This means that he assumes that a causal relation is either present or absent in each case. The procedure involves successively reducing the complexity of the configurations by eliminating variables not having any bearing on the outcome, and by, in the next stage, looking for 'surplus terms' employing algebra. Ragin's rule bears close resemblance to Mill's canons:

If two rows of a truth table differ on only one causal condition yet result in the same outcome, then the causal condition that distinguishes the two rows can be considered irrelevant and can be removed to create a simpler combination of causal conditions. ${ }^{21}$

So even if the concept of configuration takes context into consideration, much information is lost during the research process. The approach is furthermore inductivist and based on Mill's canons, and is therefore a synchronic and correlational analysis lacking in explanatory depth. Additionally, Peter Wad raises a critique of Ragin's notion of causality as deterministic, or at least stochastic. ${ }^{22}$

\footnotetext{
17 Ibid.

18 Bacon, cited in Hammersley et al., CST, 242.

19 Ragin, CSR.

20 Ragin, CSR; Peter Wad, CRCS.

21 Ragin, CSR, 125.

22 Wad, 'Komparation'.
} 


\subsection{Inductive inferences}

According to Danermark et al., different modes of inference are foundational for how researchers develop, test and apply concepts and theories. ${ }^{23}$ Being associated with case studies, comparative research is often tied to inductive inferences. However, in what follows we shall see how different inductive procedures involve quite different philosophies.

First, comparative case studies might employ what Hammersley et al. term eliminative induction with a view to identifying necessary and sufficient causal mechanisms, as opposed to only the necessary ones, as usually induced in qualitative methods. ${ }^{24}$ The procedure often involves drawing up matrices checking for presence or absence of selected explanatory variables in order to eliminate variables not having any bearing on the outcome. ${ }^{25}$ This approach often draws explicitly on Mill's above-mentioned methods. Identifying necessary conditions for a given outcome involves examining cases with the same outcome and checking which variables they have in common. On the other hand, examining cases with differences in outcome, and hence eliminating variables not affecting the outcome, is necessary in order to arrive at the sufficient conditions for explaining the outcome. ${ }^{26} \mathrm{~A}$ main problem with this form of comparative method is, as already stated, that the elimination of false explanations is reliant on having included all the relevant features of the cases selected. And, according to Hammersley et al., if features of cases are not simply evident to our senses, their identification involves a process of conceptualisation. ${ }^{27}$ The role of theory in selecting among potential explanatory factors cannot, in other words, be denied or simply neglected. Another problem is the number of cases needed if the study aspires to arrive at causal explanations on the basis of regularities, since this requires that every relevant case be studied. And, furthermore, since this includes all the cases occurring in the past, present and future, the number is infinite. The importance of a large number of cases is even clearer if the potential causal role of absences of particular events and combinations of features are taken into account. This is due to relying on abstracting by generalising; that is, regularities across cases are presumed to be essential and thus abstracted because of this generality. ${ }^{28}$ Generalisation is here based on induction, and aspires to reach universally applicable conclusions from observations

23 Danermark et al., ES.

24 Hammersley et al., CST.

25 Ragin, CSR.

26 Hammersley et al., CST.

27 Ibid.

28 Znaniecki, cited in J. Clyde Mitchell, 'Case and situation analysis', in Case Study Method: Key Issues, Key Texts, eds R. Gomm et al. (London: Sage, 2000). 
of a limited number of events or phenomena. ${ }^{29}$ Regularities are hence held to persist and are often treated as laws. ${ }^{30}$

The second mode of inference identified by Hammersley et al. is analytic induction as conceived by Florian Znaniecki. ${ }^{31}$ According to the latter, causation involves necessity, and causal analysis implies defining the essential features of what is to be explained. The aim of comparison here is to arrive at explanations by refining and reformulating rather than to eliminate false ones. A critique of analytic induction is that it can only lead to the identification of necessary and not sufficient conditions, since the cases studied for the most part are ones where the phenomena to be explained are present. However, this is more a critique of the praxis than of the possibilities as there is nothing about analytic induction that forecloses the inclusion of negative cases. In contrast to the abstraction by generalisation involved in eliminative induction, analytic induction seeks to generalise by abstracting characteristics of cases thought to be essential, presuming generality precisely because they are essential. ${ }^{32}$ The procedure does not develop a self-sufficient theory by analysing one case thoroughly, but rather by examining a number of cases selected in order to illustrate formerly obscure elements of a general theory. Since one case is likely to manifest only some of the elements whose explication is needed in order to develop theory, an indeterminate number of strategically selected cases are necessary.

\section{Comparative Case Studies and Critical Realism}

In this section I give a brief outline of the philosophy of critical realism and provide some arguments why comparative case studies might be an applicable and useful method. I argue that comparative case studies informed by critical realist philosophy will be abductive and retroductive, letting theory inform the selection of cases while using the collected data to refine theoretical understandings. The realist ontology implies that reality exists relatively or absolutely independently of human consciousness of it, and epistemologically it entails that our knowledge of it is always fallible, although all knowledge is not equally fallible. ${ }^{33}$ Hence, contrary to the view among empiricists that reality is what is given in our experience of it, critical realists hold that reality must be given if researchers are able to investigate causal relations, but that our knowledge of

\footnotetext{
29 Danermark et al., ES.

30 Lawson, $R E$.

31 Hammersley et al., CST.

32 Znaniecki, cited in Mitchell, 'Case and situation'.

33 Yeung, 'Critical realism and realist research'.
} 
it is socially produced. ${ }^{34}$ It follows from this that relativism is rejected, and by ascribing causal powers to human motives and social structures, critical realism has emancipation as an ultimate goal. ${ }^{35}$

\subsection{Causality as immanent powers}

Contrary to traditional realism, critical realism is based on an ontology that is deep, differentiated and stratified. ${ }^{36}$ And contrary to empiricism, critical realism is based on an assumption of natural necessity. ${ }^{37}$ In addition to recognising that social event regularities are hard to come by, critical realists do not adhere to the view that causes are, and can be sought out by, such regularities. Rather, it is argued that regularities cannot offer any insights into anything but empirical regularities and statistical correlations. Consequently, regularities can, in open systems, at best be indicative of active mechanisms. ${ }^{38}$ Lawson has termed such imperfect event regularities 'demi-regularities' or 'demi-regs' . ${ }^{39}$ The imperfect nature of regularities is due to the distinction between the three ontological domains: the empirical, the actual and the real. ${ }^{40}$ The empirical domain consists of our experiences, and the (demi-)regularities treated as causes in the approach outlined above are hence part of this domain. However, critical realists argue that what happens in the world is not equal to what is observed, thus the actual domain consists of events that happen regardless of our apprehension of them. The domain of the real consists of that which produces the events happening at the domain of the actual, that is, structures and mechanisms. An object is what it is by virtue of its properties, and it possesses causal powers by virtue of its structures. While there is an internal and necessary relation between the nature of an object and its causal powers, the relation between these causal powers and their effect is external and contingent. Hence empirical data reflect only the tip of the iceberg. ${ }^{41}$ While structures have certain liabilities and predispositions, individual and contingent processes precipitate and determine actual outcomes. Rather than reducing what is to what we can know about it through observation, critical realists seek to 'investigate and identify relation-

\footnotetext{
34 Roy Bhaskar, Reclaiming Reality: A Critical Introduction to Contemporary Philosophy (London: Verso, 1989).

35 Yeung, 'Critical realism and realist research'.

36 Wad, 'Komparation'.

37 Danermark et al., ES.

38 Douglas V. Porpora, 'Do realists run regressions?' in After Postmodernism: An Introduction to Critical Realism, eds J. López and G. Potter (London: Continuum, 2001).

39 Lawson, RE.

40 Danermark et al., ES.

41 Wad, 'Komparation'.
} 
ships and non-relationships, respectively, between what we experience, what actually happens, and the underlying mechanisms that produce the events in the world'. ${ }^{42}$ The structures and mechanisms are thus real and distinct from the patterns of events they generate, and, in turn, our experience of the events. ${ }^{43}$ In other words, mechanisms do not act actualistically, that is, they do not result in the same actual events or outcomes, but transfactually, meaning that they are always in play regardless of the outcome. ${ }^{44}$ Critical realism will thus guard against treating actualities, or events, as being the sole constituents of the world, and against expecting particular conjunctions of events necessarily to be recurrent. Explanation involves a movement from observed phenomena at one level to their underlying causes at another, and deeper, level, and is possible without any stable event regularities being uncovered. ${ }^{45}$ Using the example of the spurious connection between the presence of storks and the number of babies, Danermark et al. argue that analyses of empirical regularities may get mixed with the discovery of causes. ${ }^{46}$ They do not, however, deny the merit of statistical investigations, but contend that they must be applied according to their capabilities. Informing about causes is not among these. From a critical realist perspective, causes are not regularities but powers and liabilities, and they 'may be possessed unexercised, exercised unrealised, and realised unperceived (or undetected) by men; they may also be transformed' ${ }^{47}$ Hence critical realists understand causality as a generative and contextual concept. ${ }^{48}$ An explanation thus requires that the generative mechanisms be studied in their context, meaning that external effects of mechanisms other than the ones internal to the object of study must be taken into account. Contextual aspects are thus important for explaining the effects, but not for theorising the potential causal powers, of an object. ${ }^{49}$ However, seeking contextless relations among variables, as positivists do, makes little sense. ${ }^{50}$ Critical realists, in line with Ragin's QCA, advocate multi-causality but, being less deterministic, apply it in both directions. ${ }^{51}$ Hence a particular mechanism might produce completely different outcomes in time and space, and a particular event can be caused by different mechanisms and itself in turn constitute a mechanism. The atomism of Hume, where cause and

42 Danermark et al., ES, 21.

43 Roy Bhaskar, 'Philosophy and scientific realism', in Critical Realism: Essential Readings, eds Margaret Archer et al. (London: Routledge, 1998).

44 Lawson, $R E$.

45 Ibid.

46 Danermark et al., ES.

47 Roy Bhaskar, A Realist Theory of Science (Hassocks: Harvester, 1978), 18.

48 Wad, 'Komparation'.

49 Wad, CRCS.

50 Porpora, 'Do realists run regressions?'.

51 Ragin, CSR. 
effect were seen as separate and independent, is in other words replaced by a view of causality as powers possessed by agents or objects and not as relations among separate categories of phenomena. Causality is furthermore conceived of as a process, and thus diachronic, and, as opposed to static abstractions, captures the dynamic dimension of reality. ${ }^{52}$

The critical realist notion of causality thus implies that we cannot look for universal laws in empirical data, and causality cannot be congruent with prediction. ${ }^{53}$ Starting from another conception of causality, comparative methods need not be about arriving at invariant associations. If atomism is denied and the possibility of gaining insight into causal relations by examining one single case is maintained, comparative method becomes a way of studying contingency and broadening the base from which to develop theory. More importantly perhaps, another consequence is that causal powers may be possessed by objects or relations even though they are not exercised. Hence regularities will not necessarily tell us anything about causality, although they might; that is, objects and relations have causal powers independently of any specific pattern of events apprehended by our senses. ${ }^{54}$ In other words, rather than being preoccupied with regularities between distinct objects and events, or cause and effect, critical realists deal with what objects or relations are and the things they can do in virtue of their nature. According to Paul Connolly, a primary goal becomes to study which and how causal relationships operate in the case(s) chosen, and not to test whether these relationships are present elsewhere. ${ }^{55}$ However, he argues that analyses must draw on accounts of causal relationships in other cases and contexts. Nonetheless, studying causal powers requires in-depth knowledge, and the approach is accordingly much more intensive than one based on the canons of Mill. The aim is not to examine regularities across all cases, or at least as many as possible, but to gain knowledge about causal relationships through in-depth analysis of a few selectively chosen cases. Comparison is needed to strengthen validity, as it is the general nature of causal claims that allows people to check what caused what in a given situation. ${ }^{56}$ Hence, explanations rely on general assumptions about causality that cannot be validated by a study based on a single case.

\footnotetext{
52 Danermark et al., ES.

53 Wad, CRCS.

54 Danermark et al., ES.

55 Referred to in Hammersley et al., CST.

56 Ibid.
} 


\subsection{Retroductive and abductive inferences}

According to Danermark et al., studies aiming at describing or theorising fundamental conditions may to great advantage be organised as comparative case studies. ${ }^{57}$ Cases are not selected primarily on the basis of differences in outcome, but rather because the cases manifest a common structure that the researcher wants to describe. For a comparison to be relevant, however, the cases should be very different in most other aspects. By working comparatively, as opposed to undertaking a single case study, it becomes possible to a greater extent to distinguish necessary conditions from contingent ones. ${ }^{58}$ Another reason why comparative case studies are favoured in the critical realist tradition is that they provide an empirical foundation for retroduction. Since qualities and structures are often hard to discern in concrete cases, systematic comparison might help the researcher both identify them and distinguish between different forms they might assume. Generalisation is here arrived at, as opposed to the extrapolation referred to above, by means of retroductive inference, and thus moving not from the particular to the universal, but from the concrete to the abstract. Hence, while deduction and induction restrict the researcher to merely considering the level of reality at which the given phenomenon occurs, retroduction allows a movement beyond the surface phenomenon. ${ }^{59}$ In addition to retroduction, critical realists often employ abductive inference. While retroduction infers by answering the question 'What made this possible?', abduction is used to identify structures when analysing empirical data. Abduction is often conceived as a dialectical movement between empirical data and theory, as, in seeking to explain an empirical event, this event is related to theory that in turn leads the researcher to new interpretation of the event. What distinguishes abduction from analytical induction is that in induction the starting-point is the empirical data, and the conclusion is a generalisation, while abduction starts from a general theory or interpretation and thus recontextualises the theory by applying it to a new context, or reinterprets a phenomenon in light of a new theoretical framework. ${ }^{60}$ It is explicitly recognised that the theory chosen is one out of several possible theories, the aim of the procedure being to provide new insight as a result of employing an alternative theory to that which is hegemonic. However, this makes it a fallible insight, and theory assumes more the role of a working hypothesis as conceived by Lee J. Cronbach. ${ }^{61}$ In stud-

57 Danermark et al., ES.

58 Ibid.

59 Lawson, $R E$.

60 Danermark et al., ES.

61 Yvonna S. Lincoln and Egon G. Guba, 'The only generalisation is: there is no generalisation', in Case Study Method: Key Issues, Key Texts, eds R. Gomm et al. (London: Sage, 2000). 
ies guided by abduction the dialectic between theoretical reinterpretation of cases or recontextualisation of theories, on the one hand, and theory refinement based on case studies, on the other, is absolutely central. ${ }^{62}$ In order to be better able to distinguish between internal relations and contingent circumstances when employing retroduction, comparing several cases is an important strategy. However, analysing the interplay of multiple mechanisms in an open world, critical realists seem to favour intensive research designs. ${ }^{63}$

A problem with comparative case studies might be that knowing what to look for requires quite extensive knowledge of the mechanisms involved in advance. Without this knowledge, important explanatory factors might be overlooked, thus impacting negatively on the validity of the research findings. Theory thus assumes an important role in working out the research strategy prior to the collection of data. It is possible to argue that extensive knowledge prior to data collection might create biases. However, the neutrality and objectivity of any kind of social research has been questioned, and the need for researchers to reflect on their role and position in the project is acknowledged. ${ }^{64}$ According to Danermark et al., every attempt, including scientific, to understand the world starts from our concepts of it. ${ }^{65}$ In critical realism the relation between the real world and the concepts we form of it has become a major focus. Hence, reality exists independently of our apprehension of it, but our experience of it is conceptually mediated. Scientific understandings of this reality are in other words theory-laden, but not theory-dependent.

\section{Towards a Critical Realist Comparative Methodology}

To me, the procedure based on the canons of Mill appears too rigorous and does not allow for contingent mechanisms and synergy between the variables, and I think it implies an oversimplification of reality. The search for regularities and the aspiration to prediction also implies an inclination to social determinism that is incompatible with studying societies in which human beings are capable of exercising free will. ${ }^{66}$ If an agent is free and able to choose to do other than some given $y$ in specific conditions $x$, searching for patterns across a wide range of cases becomes fraught with difficulty. ${ }^{67}$ Critical realists such as Margaret

62 Danermark et al., ES.

63 Porpora, 'Do realists run regressions?'.

64 Mats Alvesson and Kaj Sköldberg, Tolkning och reflektion: vetenskapsfilosofi och kvalitativ metod (Lund: Studentlitteratur, 1994).

65 Danermark et al., ES.

66 Hammersley et al., CST.

67 Lawson, $R E$. 
Archer have argued that in the social sphere there are properties and powers particular to people, for instance, reflexivity and creativity in relation to the context, which preclude any experimental closure. ${ }^{68} \mathrm{~A}$ merit of rigorous approaches is that they are systematic and orderly, but this is at the expense of studying the context. I try to avoid the disadvantages recognised above by favouring context and nuances over a systematic approach, thus allowing for contingencies. Instead of the eliminative induction based on more than 15 cases exemplified in Ragin's QCA, I agree with Hammersley et al.'s redirection towards analytic induction based on fewer cases. ${ }^{69}$ The justification of this reduction in number of cases is grounded in the notion of causality applied. Despite an increased number of cases, comparative case studies do not offer a greater opportunity for making generalisations in the statistical sense of the term anyway. First of all, the number of cases is far too low, and, secondly, the cases are not selected randomly. I turn now to how critical realism might form the backbone of an alternative approach to comparative case studies. According to Wad, however, such an approach is yet to be formulated, so my aim is to provide only some initial steps. ${ }^{70}$

Before embarking on that task, however, a brief consideration of Lawson's contrast explanation is warranted, as this provides very valuable insights into how the operation of generative mechanisms could be identified through comparison. ${ }^{71}$ Lawson takes as a point of departure the fact that people are quite successful every day in negotiating the complex social world, and he asks how knowledge of the world is advanced. The answer he provides is that people often question why something is not quite as expected, and that such surprised expectations are everyday occurrences. He holds, furthermore, that this has significant import for social scientific research through contrast explanation. Contrast explanation seeks to answer the question 'Why $x$ rather than $y$ in conditions where $y$ was expected?', and the explanation offered is not of $x$ per se, but of the contrast ' $x$ rather than $y$ '. The focus is thus not primarily on the outcome, but on comparing or contrasting the cases where $x$ and $y$ have occurred respectively. There are, according to Lawson, two necessary conditions for successful contrast explanation. First, there must be a domain over which comparison is meaningful and, secondly, all relevant aspects, except the one making the cases different, must be correctly assessed to be subject to more or less the same set of causal influence. Contrast explanation can be used in initiating an

68 Margaret Archer, 'Introduction: realism in the social sciences', in Critical Realism: Essential Readings, eds Margaret Archer et al. (London: Routledge, 1998).

69 Ragin, CSR; Hammersley et al., CST.

70 Wad, 'Komparation'.

71 Lawson, $R E$. 
explanatory process by focusing on surprise, but also in directing the explanatory process by explaining the discrepancy between outcomes. By directing the attention to the (set of) mechanism(s) explaining diverging outcomes, contrast explanation draws heavily on Mill's method of difference: 'By attempting to explain ... the observed contrast ... factors common to all ... can be standardised for, or factored out, allowing the possibility of identifying the (specific or most direct) cause'. ${ }^{72}$ Lawson does acknowledge this inspiration in one of his endnotes, and renders, in this sense, contrast explanation Millean. In discriminating between competing causal hypotheses, the researcher is again advised to seek out contrasts on which these hypotheses bear, that is, perform a more or less predictive test of their empirical adequacy. Hence Lawson invokes deductive logic when he proposes a way of 'testing' hypotheses:

In the case of each hypothesis in contention, inferences are drawn concerning contrasts that we might expect to find. In each case it is inferred that if the hypothesis is correct, [the outcome will be more prevalent] in the region of the contrast space closest to the hypothesised mechanism in question. ${ }^{73}$

It seems to me that instead of shifting the focus away from regularities after acknowledging that they are rare in the social world, Lawson's approach seeks to adjust experimental activities to make them fit the social sciences and hence uphold the central status of (demi-)regularities. Acknowledging that social reality is open and that social events will rarely be clear-cut, it is my opinion that instead of opting for a simplifying and systematic approach, the complex nature of the social world ought to be reflected in a complex methodology. On the other hand, Lawson does not stylise the identified demi-regs, nor utilise them solely for prediction, but he rather regards them as 'a moment in the causal process which goes beyond them'. ${ }^{74}$ Demi-regs are important in forming our expectations and are seen to provide an indication of the working of a causal mechanism; they are also instrumental, as seen above, in directing scientific investigations. I agree with Lawson that a surprised expectation, or contrast, might be a good point of departure for awakening our analytical senses, and that regularities might be indicative of active mechanisms, but in my opinion the imperfection of regularities in the social world ought to make researchers wary of stretching what they can offer. Hence, I argue that, in addition to letting surprised expectations of external differences among cases initiate an explanatory process, researchers need to conduct an internal analysis of each case. Instead of standardising for, or factoring out, factors common to all cases, internal analysis might reveal how the common factors manifest

\footnotetext{
72 Ibid., 95.

73 Ibid., 97.

74 Ibid., 102.
} 
themselves differently in different contexts. For example, a factor common to trade unions in Europe is that they regard themselves to varying degrees as 'social partners' with government and capital. However, the consequences of this ideology in a particular industrial dispute may play out differently in each case depending on several contextual and contingent factors such as the outlook and militancy of both the workers involved and the particular union official(s). 'Social partnership' can, in other words, be an interesting similarity between German trade unions being involved in concessionary bargaining and Irish trade unions having members barricaded in a ship's engine room for three weeks, and should not be standardised for or factored out, as an analysis of it might enhance our understanding of the ideology of social partnership and how it can function both as a cause and a mediator of events. Another example where internal analysis would be important is in explaining the contrast in economic achievement between East and Southeast Asia, on the one hand, and Africa, on the other. This presupposes that the contrast spaces have a similar causal history. Although this presupposition is not unusual in the field of development theory, writers such as Philip Kelly have demonstrated the contrary; there is an enormous diversity of development experiences even among the countries of Southeast Asia. ${ }^{75}$ Any explanation of the contrast to Africa should thus be supplemented by an internal analysis of each case, that is, each of the countries of East and Southeast Asia and of Africa, and their differences need not be contrasts. I now turn to the task of further developing a critical realist approach to comparative method, one not incompatible with Lawson's, but supplemented with a more contextual scrutiny of each case.

\subsection{Theoretical and abductive comparison}

Danermark et al. argue that it is restricting to think of method as having primarily to do with data collection and empirical analysis, since an essential part of it is employing and developing theories. ${ }^{76}$ According to Victoria Bonnell, it is essential to consider, not only the type of theories employed, but also the function they perform. ${ }^{77}$ This relates both to the relation between theory and empirical data and to the form of comparison. Bonnell differentiates between two forms of comparison, which she terms 'analytical' and 'illustrative', relying

75 Philip F. Kelly, 'Spaces of labour control: comparative perspectives from Southeast Asia', Transactions of the Institute of British Geographers 27(4) (2002), 395-411, doi:10.1111/14755661.00062 .

76 Danermark et al., ES.

77 Victoria E. Bonnell, 'The uses of theory, concepts and comparison in historical sociology', Comparative Studies in Society and History 22(2) (1980), 156-73. 
on two different meanings of 'comparison'. The former is based on comparison between or among cases, and is used in explanations of patterns of similarity and difference by inductively discerning regularities, as, for instance, in Ragin's approach. ${ }^{78}$ In illustrative, or theoretical, comparison, on the other hand, the researcher compares several cases as they relate to one or more theories applicable to all of them in order to identify and clarify the function of constituent elements, that is, analysing in terms of substantial and contextual relations. ${ }^{79}$ This approach is thus not inductive and can, as we shall see, sit well with abductive inferences, and it implies a two-pronged conceptualisation of 'comparison' involving both comparing theory as it relates to each case and comparing across the factual cases in light of the theory. Here it is important to reiterate the distinction between critical realism and empiricism, as theory in the first instance is not associated with generality in the sense of repeated series of events, but with structures. Furthermore, by employing abductive and retroductive inferences, already existing theories are seen as a resource rather than a bias-creating impediment to induction. Operating with a partly non-observable reality, theories may help us gain knowledge of structures and mechanisms, which can hardly be attained through induction. General theories should thus be used to formulate interesting and relevant questions in concrete studies paying heed to specific contextual circumstances. Abduction entails reinterpretation and recontextualisation, as researchers take their starting-point in a theoretical framework and thereby interpret and assign new meaning to the phenomenon under study or develop theory by applying it in new contexts. Classifying without being guided by theory might, according to Danermark et al., run the risk of being short-sighted, narrow, naïve and without critical potential. ${ }^{80}$ Reinterpretation of empirical data should, in other words, aim at challenging common-sense categorisations and explanations. There are two ways of comparing when taking theories as the point of departure; comparing the explanatory power of different theories on the same empirical data, or applying theories across several empirical fields. The latter is closest to the traditional comparative case study, and seeks to assess the explanatory power of a theory, being applicable to one case, when applied to additional cases. ${ }^{81}$ Both entail an evaluation of theories with reference to their merits as interpretative frameworks and not through empirical verification/falsification. Cases are chosen selectively and are assumed to manifest the structure that the theory describes, although they should be different in other respects. This procedure could contribute to

\footnotetext{
78 Ragin, CSR.

79 Bonnell, 'The uses of theory'.

80 Danermark et al., ES.

81 Bonnell, 'The uses of theory'.
} 
increased knowledge of the workings of a structure while also providing a foundation for sorting out contingent and accidental circumstances. ${ }^{82}$

\subsection{Context-sensitivity}

According to Danermark et al., the phenomena studied by social scientists are contextually defined, and to be able to explain, researchers need to study how mechanisms are manifested in concrete contexts. ${ }^{83}$ In order to gain knowledge of both a general and a contextual kind, the combination of intensive and extensive research designs is proposed. Extending this to comparative case studies, the analytical and the illustrative forms of comparison need not be regarded as mutually exclusive. ${ }^{84}$ Thomas Janoski and Alexander Hicks propose a strategy of supplementing an external comparative analysis among cases with an internal examination of each case, and this can be related to the distinction between analytical and illustrative forms ${ }^{85}$ While the external analysis identifies similarities and differences among the cases, the internal analysis is conducted in order to gain explanatory depth. However, since emphasis can be placed on one or the other, it is important to stress that in order to term the approach 'theoretical comparison', the external comparison of similarities and differences ought only to be preliminary, although important in the selection of cases. The depth attained by internal analysis of each case, coupled with the scope achieved through external comparison, becomes particularly important when the interaction between, and maybe even the interdependence of, the cases in question is acknowledged. If, for example, a researcher is to analyse the relative strength of trade unions organising in different industrial sectors by looking at the outcomes of several actions, any outcome could be the result of that trade union's efforts and leverage, but also of assistance from, or even cooperation with, others. In order to determine what is the case, the external analysis of similarities and differences in achievements should be supplemented by an internal analysis engaging the particular unfolding of events.

The procedure Janoski and Hicks propose consists first of formulating a research problem and finding a theoretical perspective, and is hence not a purely inductive approach, although Wad contends that their methodological

82 Danermark et al., ES.

83 Ibid.

84 Bonnell, 'The uses of theory'.

85 Thomas Janoski and Alexander M. Hicks, 'Methodological innovations in comparative political economy: an introduction', in The Comparative Political Economy of the Welfare State, eds Janoski and Hicks (Cambridge: Cambridge University Press, 1994). 
backbone is Millean. ${ }^{86}$ Already established theories are, as in critical realism, not regarded as impediments and biases, but rather as a resource. The mode of inference is, as already mentioned, abduction, although Janoski and Hicks seem to regard it as a procedure to avoid biases. However, the critical realist notion of abduction where, unlike induction, the researcher starts from a theory and, unlike deduction, does not arrive at a conclusion that is logically given in the premises, would be applicable to their procedure. ${ }^{87}$ The aim is moving from one conception of something to a new, and hopefully more developed, conception of it. Danermark et al. term this a 'recontextualisation' since it entails interpreting and explaining a phenomenon within the framework of a new set of ideas or a new context, but I prefer the term 'reinterpretation' for the act of employing a new set of theories on already known phenomena. ${ }^{88}$ The next step involves selecting cases, and this is not done randomly but, on the contrary, selectively on the basis of a belief that they exhibit the operation of the structures and mechanisms delineated by the theoretical perspective chosen as the framework. In other words, instead of trying to develop a theory inductively, the researcher ought to examine cases that are consciously selected in order to illuminate and further develop formerly obscure or undertheorised aspects of the general theoretical framework. ${ }^{89}$ During and after the selection of cases a preliminary external comparative analysis of their similarities and dissimilarities is conducted. However, when this is done the researcher supplements the comparisons of characteristics between cases with data collection and internal analyses of each case in its own right, paying heed to context and laying the groundwork for the theoretical comparison. Hence, in addition to the theories needed to explain internal dynamics, each case is compared in relation to the theoretical framework. By applying the theories to different contexts, the researcher is, in that process, forced to adapt them to each specific case, but with a view to discerning, in the end, the general as distinct from the contingent. In other words, a general theory might be applicable to several cases, but the mechanisms it depicts may play out differently in different contexts. This was seen in the example provided above, where theories of class compromise and social partnership would be applicable to analyses of both German and of Irish trade unionism, but where analyses of concrete trade union practice reveal how its manifestation may vary. The internal analysis is thus an iterative process, although the researcher is simultaneously cognizant

\footnotetext{
86 Ibid.; Wad, CRCS.

87 Danermark et al., ES.

88 Ibid.

89 Mitchell, 'Case and situation'.
} 
of the internal analyses undertaken in the other cases. ${ }^{90}$ Adapting the general theory to specific circumstances and comparing them might, in the next instance, refine the theory in its general aspects. The last step consists of analysing the interconnections between, on the one hand, the (dis)similarities among cases identified in the external analysis and, on the other, the operation of structures and mechanisms in each case found in the internal analysis, with a view to reformulating the theoretical framework outlined at the very start. Again, this is compatible with abduction since it entails a flexible interaction between conceptualisation and analysis, and in research practice guided by abduction 'the interplay (dialectic) between theoretical redescriptions of cases and case-study-based theory development is absolutely central'. ${ }^{91}$ Theory is thus not regarded as a ready-made product, but rather as a certain way of viewing reality informing the questions asked and the interpretation of data in concrete research. While the preliminary external analysis identifies the similarities and differences between the cases and is driven by a theoretical interest in explaining them, the internal analysis employs theory by interpreting each case, and thereby provides the basis for the next round of comparison. By employing the same theoretical framework across cases, new light will be shed both on the theories and on the cases, and the theories will provide an ordering framework helping the researcher to know what to look for in the internal analysis. Observable empirical regularities can thus be used as a starting-point in the selection of theoretically interesting cases and in an attempt to discern properties of the object by studying it in its context. The context cannot be regarded as an unwanted nuance to be eliminated, as it conditions whether and how causal powers are actualised.

Through comparative case studies a researcher might achieve a reinterpretation by placing the phenomena in a new interpretative framework, but also a recontextualisation by comparing the different cases. In the process, the researcher might discover new aspects of the cases selected, resulting in a broadened imagination spawning ideas as to how each case can be interpreted. By comparing different cases, the aim is to shed light on common abstract processes that, at first sight, might not appear to be empirical similarities. For instance, by comparing the plight of trade unions striving to organise in a garment factory in an Export Processing Zone (EPZ) in Namibia with the challenges an Irish trade union meets in unionising workers on board ships, a researcher can come to see how the different contexts of EPZs and ships might manifest similar structural constraints on trade unions.

90 Janoski and Hicks, 'Methodological'.

91 Danermark et al., ES, 95. 
The two types of theoretical comparison, that is, comparing different theories on one case and, on the other hand, a set of theories across many cases, can be combined when further developing Janoski and Hick's procedure. The framework of interpretation employed in the internal analysis constitutes one out of several possible ones, and in the analysis the theories are compared to find out which provides new insight and has the most explanatory power. Externally the set of theories act as a common framework for interpretation, and is thus applied to all cases.

\section{An Illustration}

In order to illustrate how the proposed methodology could be practised, I now provide an example from my own research. My point of departure being to further develop theories on global trade unionism, I was at first inspired by the contrasts in achievement among the Global Union Federations (GUFs). In conducting the preliminary external analysis, I selected the three cases that were most contrastive and that varied in theoretically interesting properties: the International Textile, Garment and Leather Workers' Federation; the International Metal Workers' Federation; and the International Transport Workers' Federation. I then collected more data on their properties and achievements with a view to comparing and, subsequently, explaining the similarities and differences so identified. However, in order to identify structures and generative mechanisms, I found it necessary to supplement this external analysis with an internal analysis of the three GUFs in their own right, employing the same theoretical framework for each of them, and thereby undertaking a theoretical comparison. By so doing, I was able to see to what extent the context and contingent factors mediated the operation of the mechanisms identified through theory in each case. Not regarding cases as hermetically sealed systems, it becomes important to compare both the common influences of the larger context of which they all are part, for instance global capitalism, and how the cases interact, for example, how a successful achievement on part of one GUF might inspire others to follow suit. In my view this necessitates an internal analysis. From the perspective of human geography it is also important to break the cases down into geographical scales delineating the structures and mechanisms both common to all and particular to each of them. For instance, the ideology of social partnership will in varying degrees be manifested at the global, national and local scale. In other words, instead of increasing the extensiveness of the comparative case study by analysing six cases externally, further understanding was sought by increasing the intensiveness by investigating three concrete sub-cases within each case as part of the internal analysis. These were 
empirical events in which one of the three GUFs was involved, and each subcase was analysed employing the same theoretical framework, although theories necessary to explain the event were added. The last step consists of conjoining the insights gained through the preceding external and internal analyses with a view to providing new insight and refining the existing theories. This is not done by describing or comparing the empirical traits of each case, but by comparing how the structures were manifested and how the mechanisms operated in the different cases. The dis(similarities) found in the external analysis are explained by this refined theoretical framework, while the contextual and empirical differences found in the internal analyses could account for different manifestations. This last step thus involves an abductive comparison with a dialectical move between theory and data across cases with a view to abstracting the internal and necessary relations. In other words, while the two preceding steps were analyses of concrete phenomena, the last step is more concerned with abstract conceptualisation.

\section{Conclusion}

While Lawson's contrast explanation might lead the initial stages of research as well as guide the external analysis, I have argued that it needs to be supplemented by the internal analysis of each case. Furthermore, theoretical comparison employing abductive and retroductive inferences allows researchers to draw inspiration from the formal procedures of comparative case studies, while not reducing their findings to variables in a matrix, but instead remaining open to the complexity of causal relations and the society as an open system. It will thus support a more interpretative, contextual approach based on a limited number of cases, and hence move an internal analysis away from a preliminary or background status to an analysis in its own right. It is furthermore important to differentiate between comparative case studies striving to explain through induction, and seeking to arrive at some kind of formula displaying necessary and sufficient conditions, on the one hand, and comparative case studies concerned with developing theories, on the other. ${ }^{92}$ This distinction is especially important when choosing an approach, since in attempts to develop theory, cases are interesting just to the extent to which they exemplify the relevant theoretical category. On the other hand, if aiming at more inductive theory generation, within a critical realist perspective much more heed needs to be paid to the distinctive features of the different cases. The selection of cases is not undertaken with a view to including all relevant cases in order to ensure

${ }_{92}$ Hammersley et al., CST. 
some degree of certainty of the inductive inferences, but rather with a view to finding cases that have significant implications for theory. Furthermore, the lawlike statements of necessary and sufficient conditions must be substituted for a focus on generative mechanisms, the outcome of which cannot be explained without due consideration of the context in which they operate and thus the contingency, as opposed to determinism, of their effect. Important principles in comparative case studies guided by critical realism are thus context-sensitivity due to contingency, and hence that induction, or basing research purely on empirical data, cannot lead to a deeper understanding of social reality.

\section{Bibliography}

Abbott, A. Time Matters: On Theory and Method. Chicago, IL: University of Chicago Press, 2001. Alvesson, M. and K. Sköldberg. Tolkning och refektion: vetenskapsfilosofi och kvalitativ metod. Lund: Studentlitteratur, 1994.

Archer, M. 'Introduction: realism in the social sciences'. In Critical Realism: Essential Readings, edited by M. Archer, R. Bhaskar, A. Collier et al., 89-206. London: Routledge, 1998.

Bhaskar, R. 'Philosophy and scientific realism'. In Critical Realism: Essential Readings, edited by M. Archer, R. Bhaskar, A. Collier et al., 16-48. London: Routledge, 1998.

Bhaskar, R. A Realist Theory of Science. Hassocks: Harvester, 1978.

Bhaskar, R. Reclaiming Reality: A Critical Introduction to Contemporary Philosophy. London: Verso, 1989.

Bonnell, V. E. 'The uses of theory, concepts and comparison in historical sociology'. Comparative Studies in Society and History 22(2) (1980): 156-73.

Danermark, B., M. Ekström, L. Jakobsen and J. C. Karlsson. Explaining Society: Critical Realism in the Social Sciences [ES]. London: Routledge, 2002.

Hammersley, M., R. Gomm and P. Foster. 'Case study and theory'. In Case Study Method: Key Issues, Key Texts, edited by R. Gomm, M. Hammersley and P. Foster, 234-58. London: Sage, 2000.

Hacking, I. Representing and Intervening: Introductory Topics in the Philosophy of Natural Science. Cambridge: Cambridge University Press, 1983.

Janoski T. and A. M. Hicks. 'Methodological innovations in comparative political economy: an introduction'. In The Comparative Political Economy of the Welfare State, edited by T. Janoski and A. M. Hicks, 1-27. Cambridge: Cambridge University Press, 1994.

Kelly, P. F. 'Spaces of labour control: comparative perspectives from Southeast Asia'. Transactions of the Institute of British Geographers 27(4) (2002): 395-411. doi:10.1111/1475-5661.00062.

Lawson, T. Reorienting Economics [RE]. London: Routledge, 2003.

Lincoln, Y. S. and E. G. Guba. 'The only generalisation is: there is no generalisation'. In Case Study Method: Key Issues, Key Texts, edited by R. Gomm, M. Hammersley and P. Foster, 27-44. London: Sage, 2000.

Mill, J. S. System of Logic, Ratiocinative and Inductive: Being a Connected View of the Principles of Evidence, and the Methods of Scientific Investigation, 5th edn. London: Parker, Son, and Bourn, 1843/1862.

Mitchell, J. C. 'Case and situation analysis'. In Case Study Method: Key Issues, Key Texts, edited by R. Gomm, M. Hammersley and P. Foster, 165-87. London: Sage, [1983] 2000.

Mjøset, L. 'Theory: conceptions in the social sciences'. In The International Encyclopedia of the Social and Behavioral Sciences, edited by N. J. Smelser and P. B. Bates, 15641-47. Oxford: Elsevier, 2001.

Porpora, D. V. 'Do realists run regressions?' In After Postmodernism: An Introduction to Critical Realism, edited by J. López, and G. Potter, 260-66. London: Continuum, 2001. 
Ragin, C. C. Constructing Social Research: The Unity and Diversity of Method [CSR]. Thousand Oaks, CA: Pine Forge Press, 1994.

Sayer, A. 'Critical realist methodology: a view from Sweden'. Fournal of Critical Realism 1(1) (2002): 168-70.

Wad, P. 'Critical realism and comparative sociology' [CRCS]. Paper presented at the 5th IACR Conference, Roskilde, 2001.

Wad, P. 'Komparation i kritisk realistisk perspektiv'. Dansk Sociologi 11(3) (2000): 7-28.

Yeung, H. W. C. 'Critical realism and realist research in human geography: a method or a philosophy in search of a method?' Progress in Human Geography 21(1) (1997): 51-74. doi:10 $.1191 / 030913297668207944$. 